\title{
P04.67. Survey on hand gestures relevance in patient practitioner communication: a homeopathic example
}

\author{
M Escher ${ }^{2}$, A Büssing ${ }^{2}$, F Escher ${ }^{1}$, T Ostermann $^{2 *}$ \\ From International Research Congress on Integrative Medicine and Health 2012 \\ Portland, Oregon, USA. 15-18 May 2012
}

\section{Purpose}

A systematic review showed that patients convey important informations in spontaneous co-speech hand gestures (HG) when presenting their complaints and describing their pain experiences. Only a minority of practitioners and therapists were reported to have actively analyzed patients' hand gestures during case taking. Sensation method (SM) homeopaths were one of the reported exceptions. This survey was designed to gain a better understanding of the perspective, usage, appraisal and general relevance of manual co-speech gestures by SM homeopaths.

\section{Methods}

Ninety-four out of 306 seminar attendants (mean age 49.6 y, $80.9 \%$ female, $57.4 \%$ physicians and $42.6 \%$ healing practitioners) at two seminars on SM homeopathy with varying degrees of expertise, answered a standardized 54-item questionnaire. For 20 items on "perspective, utilization and relevance of gestures in patients' symptom description" a factor analysis was performed, by means of principal components analysis and varimax rotation to arrive at a solution that demonstrates both the best simple structure and the most coherence. Nine items were excluded after reliability analysis due to low item total correlations.

\section{Results}

Eleven remaining items formed a set of three factors explaining $66.6 \%$ of variance. The first factor with five items describes "Hand gestures in relation to verbal expressions" $(\alpha=0.81)$. The second factor includes four items regarding "Hand Gestures describing the experience of bodily and mental symptoms" $(\alpha=0.74)$. The third

${ }^{2}$ University of Witten/Herdecke, Center for Integrative Medicine, Herdecke, Germany

Full list of author information is available at the end of the article factor is regarding the "practitioners' behaviour and active attitude in observing hand gestures" ( $\alpha=0.86)$.

\section{Conclusion}

This survey shows how SM homeopaths actively observe HG and judge them to help patients in expressing their symptoms qualities and illness experience. Whether this view is shared by other physicians or medical professions should be investigated in the future.

\section{Author details}

'University of Witten/Herdecke, Academic Practice, Hagen, Germany.

${ }^{2}$ University of Witten/Herdecke, Center for Integrative Medicine, Herdecke, Germany.

Published: 12 June 2012

doi:10.1186/1472-6882-12-S1-P337

Cite this article as: Escher et al.: P04.67. Survey on hand gestures relevance in patient practitioner communication: a homeopathic example. BMC Complementary and Alternative Medicine 2012 12(Suppl 1): P337.

Submit your next manuscript to BioMed Central and take full advantage of:

- Convenient online submission

- Thorough peer review

- No space constraints or color figure charges

- Immediate publication on acceptance

- Inclusion in PubMed, CAS, Scopus and Google Scholar

- Research which is freely available for redistribution
C Biomed Central

(C) 2012 Escher et al; licensee BioMed Central Ltd. This is an Open Access article distributed under the terms of the Creative Commons Attribution License (http://creativecommons.org/licenses/by/2.0), which permits unrestricted use, distribution, and reproduction in any medium, provided the original work is properly cited. 